\title{
Afet Yönetim Sürecinde Rol Alacak Paydaşların Risk Algilari
}

\author{
Risk Perceptions of Stakeholders Which Will Be A Role in The Disaster \\ Management Process
}

\section{Öz}

Afetler, ülkeler için hasar verebilme potansiyelleri yüksek olan olgulardır ve afetlere karşı müdahale, hazırlı, zarar azaltma ve yeniden yapılandırma çabalarının olumlu bir sonuç verebilmesi adına paydaşlar belirlenmiştir. Buradan hareketle yürütülen çalışmanın amacı, afet yönetim sürecinde rol ve sorumluluklar bulunan paydaşlarn, afetlere yönelik risk algı düzeylerinin belirlenmesidir. Çalışma, 2018-2019 Bahar Yarıyılında Gümüşhane Üniversitesi'nde yürütülmüştür. Araştırma yöntemi betimsel araştırma olarak tasarlanmış nitel bir çalışmadır. Çalışmada yarı yapılandırılmış görüşme tekniği kullanılmıştır. Araştırma verileri araştırmacılar tarafindan hazırlanmış, nitel veri toplama tekniklerinden yarı yapılandırılmış görüşme formları aracılığıyla toplanmıştır. Veri kaynakları ise bölüm başkanlarının acil durum ve afetlere karşı risk algıların değerlendirmek için "yarı yapılandırılmış mülakat formu” ortaya çıkarılmıştır. Çalışma sonucunda bölgenin afetselliği değerlendirildiğinde düşük tehlike arz eden deprem olgusu, katılımcilar tarafindan en çok korkulan afet olarak algılandı̆̆ı saptanmıştır. Çalışmamız kapsamında, bölümlerinde afetlere yönelik eğitim içeriklerine ve afetlerin hazırlık, zarar azaltma, müdahale ve iyileştirme aşamalarında çeşitli uzmanlik ve rollere sahip paydaşların risk algıları değerlendirildiğinde plan yapma ve risk azaltma aşamalarında etkinliklerinin yetersiz olduğu sonucuna varılmıştır.

\section{Abstract}

Disasters are phenomena with a high potential to cause damage for countries, and stakeholders have been identified so that disaster response, preparedness, mitigation and restructuring efforts can yield a positive result.

The study was carried out in Gümüşhane University in 2018-2019 Spring Semester. The research method is a qualitative study designed as descriptive research. Semi-structured interview technique was used in the study. Research data were collected through semi-structured interview forms, one of qualitative data collection techniques prepared by the researchers. On the other hand, "semi-structured interview form" was created for data sources to evaluate the risk perceptions of department heads against emergencies and disasters.

The data were obtained by examining the oral interviews. On the other hand, "semi-structured interview form" was created for data sources to evaluate the risk perceptions of department heads against emergencies and disasters. As a result of the study, when the disaster nature of the region was evaluated, it was determined that the earthquake with low danger was perceived as the most feared disaster by the participants.

Within the scope of our study, when the risk perceptions of stakeholders who have various expertise and roles in disaster preparedness, mitigation, response and recovery stages were evaluated, it was concluded that their effectiveness in planning and risk reduction stages was insufficient.

\author{
Melikşah Turan \\ Öğr. Gör., Gümüşhane Üniversitesi, \\ shahturan@gmail.com \\ Orcid: 0000-0002-0588-2191

\section{Lokman Odabaş \\ Yüksek Lisans Mezun, Gümüşhane \\ Üniversitesi, odabaslokman@gmail.com \\ Orcid: 0000-0003-4717-7076}

\section{Öznur Çinar}

Yüksek Lisans Mezun, Gümüşhane Üniversitesi, oznurcnarr@gmail.com Orcid: 0000-0001-5367-9449

\section{Melike Akbaş}

Yüksek Lisans, Çanakkale 18 Mart Üniversitesi, akbaşmelike96@gmail.com Orcid: 0000-0003-4370-6356

\section{Hasan Kılıç \\ Yüksek Lisans , Gümüşhane \\ Üniversitesi, hasanayay29@gmail.com \\ Orcid: 0000-0002-8396-7369}

\section{Article Type / Makale Türü \\ Research Article / Araştırma Makalesi}

\section{Anahtar Kelimeler \\ Afet Yönetimi, Rik, Risk Algısı}

\section{Keywords}

Disaster Management, Risk, Risk Perception

JEL Codes: E69,E60, E65

$\begin{array}{ll}\text { Submitted: } & 03 / 04 / 2021 \\ \text { Accepted: } & 19 / 05 / 2021\end{array}$ 


\section{Giriş}

Afetler, bilinen veya bilinmeyen tehdit olarak nitelendirilen bir tehlike ile başlamaktadır. Tetikleyicileri ise; afetin başlangıcında yatan ciddi olumsuz etkilere neden olma potansiyeline sahip insan, doğa, teknik ve nükleer etkenlerden oluşabilmektedir. Hasar oluştuğunda veya zararlar ölçülebilir hale geldiğinde ise artık tehlike; afet sonucuna ulaşmıştır (Thywissen, 2006: 35-36). Başlıca sonuçları arasında can kaybı, yaralanma, hastalık ve insan için bedensel, zihinsel ve sosyal durum üzerindeki diğer olumsuz etkiler, maddi hasar, varlıkların yok olması, hizmet kaybı, sosyal, ekonomik ve çevresel bozulmalar yer almaktadır (www.unisdr.org, 2009). Afetleri yönetmek ise tehlikelerden kaynaklanan potansiyel zararları azaltmayı veya önlemeyi, afete maruz kalanlara hılı ve uygun yardım ile etkin iyileşme koşulları sağlamayı amaçlayan süreçler bütünü olarak ifade edilebilir (Bang, 2009: 221-225).

Afet yönetiminin temel bileşenlerinden olan risk, bir kayıp olasılığı olup tehlike, zarar görebilirlik ve maruziyet durumuna bağlı olarak ortaya çıkmaktadır. Risk altındaki bu üç unsurdan herhangi biri artar veya azalırsa, risk artmakta veya azalmaktadır (Crichton, 1999: 102-103). Risk yönetimi potansiyel zarar ve kayıpları minimize etmek amacıyla belirsizliklerin yönetimi için gerçekleştirilen sistematik yaklaşım ve uygulamalar olarak tanımlanmaktadır (UNISDR, 2009: 11).

Risk algısı kavramsal olarak incelendiğinde, faaliyetlerin belirsiz etkileri ile ilgili sinyalleri seçme ve yorumlama süreci olarak karşımıza çıkmaktadır. Bu sinyaller doğrudan gözlem yolu ile veya dişarıdan gelen bilgi yolu ile oluşur. Algılar ise riskin türü, riskin içeriği bireyin kişiliği ve sosyal içerik gibi ölçütlere bağlı olarak değişmektedir. Bir tehlikenin risk algısı açısından nerede olduğunu bilmek, politika yapıcılara ilgili durumlara karşı hazır olma konusunda fayda sağlamaktadır (Wachinger vd., 2010: 30-32).

Risk alg1s1, etkinliklerin veya faaliyetlerin belirsiz etkileri ile ilgili sinyalleri seçme ve yorumlama sürecidir. Bu sinyaller doğrudan gözlem yolu ile veya dışarıdan gelen bir bilgi yolu ile olabilir. Algılar riskin türüne, riskin içeriğine bireyin kişiliğine ve sosyal içeriğe bağlı olarak değişmektedir (Wachinger ve Renn, 2010: 8).

Riskin nasıl anlaşıldığı kısmen, riskin çalışıldığı teorik bakış açılarına ve insan davranışlarının incelenmesine ilişkin paradigmalara bağlıdır. Risklerin doğru algılanması; doğal tehlikelerle, risk azaltma konusunda afet yönetimi politikasını ve afetlerden etkilenen nüfusun, riskli bölgelerde yer değiştirilmesi için alınan kararları etkilemektedir (Renn, 2008: 65-66; Renn ve Klinke, 2001: 293; Kemp vd., 2002; Bang 2009: 37-38).

Algilanan risk, birinin öznel olasılık tahminlerinin bir fonksiyonu olarak kabul edilir ve karar vericinin belirli bir seçim yapmaya çalışırken kabul etmeye istekli olduğu, belirsiz sonuçlar hakkındaki olay kümesi olarak gösterilir. Sübjektif olasılık tahminleri için geçerlilik kriterleri, yalnızca karar teorisinin aksiyonlarına dayanır. Bu nedenle, farklı karar vericiler aynı olay kümesi için farklı öznel olasılık tahminlerine bağlı olabilirler ve bu öznel tahminlerin mutlaka nesnel olarak türetilmiş olasılık tahminlerine uyması gerekmemektedir (Cole, 1981: 144).

Risk algılarının davranışsal süreçte önemli bir rol oynadığı düşünülmektedir (Rouyard vd., 2017: 467). Bireyler risk algılamasındaki yanlışlıklar sebebiyle zarar görebilirler. (Fischhoff vd., 1993: 184). Toplumsal açıdan bakış açısı olarak risk kavramının ne şekilde algılandığının doğru bir şekilde saptanması, karşılaşılan riskli durumlara nasıl tepki verilmesi gerektiği ve yapılması gereken durumların neler olduğu saptadığından önem arz etmektedir (Çakır, 2012: 96-97).

Risklerin algılanması, olayların, etkinliklerin veya teknolojilerin belirsiz tesiri üzerine bilgi edinme, öğrenip değerlendirme sürecini kapsar. Alg1 risklerin çeşidine, risk durumuna, kişilerin bireysel ve sosyal yaşantısına bağlı olarak değişiklik gösterebilir (Renn, 2008; 31-58).

\section{Materyal Metod}

\subsection{Araştırmanın Yöntemi}

Bu çalışmada 2019 bahar yarıyılı, Gümüşhane Üniversitesi bünyesinde afet yönetim sürecinde rol alacak paydaşların, görev aldığı birimde veya sosyal hayatında, olası bir acil durum ve afet potansiyeline karşı olan risk algılarının belirlenmesi amaçlanmıştır (Tablo 1). Görüşmeler üniversal eğitim koordinatörlerinin ofislerinde gerçekleştirilmiştir. Araştırmanın amacı gereği, görüşme 
süreleri değişiklik gösterse de 30-35 dakikalık görüşmeler ile yapılmıştır. Görüşmeler, ses kayıt cihazı ile kaydedilmiştir. Derinlemesine görüşmelerin tamamlanmasının ardından da ses dokümanları deşifre edilip sorular doğrultusunda veriler çözümlenmiştir. Çözümlenen veriler tekrar gözden geçirilmiştir. Veriler, afet yönetimi alanından iki araştırmacı tarafından birbirlerinden bağımsız olarak analiz edilerek yorumlanmıştır. İçerik analizi yoluyla analiz edilmiştir. Araştırmada, içerik analizi sonucu veriler kodlanarak temalar ve alt temalar belirlenmiştir. İçerikler doğrudan alıntılarla desteklenmiştir.

Çalışma kapsamında verilerin metne dönüştürülmesi ve değerlendirilmesi araştırmacılar tarafından yapılmıştır. Mülakat formu ile elde edilen veriler, akademik etik gereği, araştırma dışında başka bir amaçla kullanılmayacaktır.

Çalışmada nitel araştırmadaki amaçlı örneklem metodlarından ölçüt örneklem metodu kullanılmıştır. Araştırmanın çalışma gurubunu Gümüşhane Üniversitesi bünyesinde 15 farklı üniversal eğitimin koordinatörleri oluşturmaktadır. Süre, kısıtlılı̆̆ından ötürü araştırmanın evreni Gümüşhane Üniversitesi bünyesinde olan, faaliyet alanı acil durum ve afetleri kapsayan paydaşlar ile sınırlandırılmış olup Türkiye genelini kapsayacak şekilde ele alınmamıştır. Bu çalışma belirleyici nitelikte olup, çalışmanın sonuçları sadece kapsam içerisindeki Gümüşhane Üniversite'sinde faaliyet gösteren, seçilen bölüm ve başkanları için geçerlidir, genelleme yapılamaz.

Tablo 1. Araştırmaya Dâhil Edilen Afet Yönetim Sürecinde Rol Alacak Paydaşların Listesi

\begin{tabular}{|c|l|c|l|}
\hline No & Bölüm Adı & No & Bölüm Adı \\
\hline $\mathbf{1}$ & Acil Yardım ve Afet Yönetimi Bölümü & $\mathbf{9}$ & İnsan Kaynakları Yönetimi Bölümü \\
\hline $\mathbf{2}$ & İş Sağlığı ve Güvenliği Bölümü & $\mathbf{1 0}$ & Uluslararası İlişkiler Bölümü \\
\hline $\mathbf{3}$ & Sosyal Hizmet Bölümü & $\mathbf{1 1}$ & Yönetim Bilişim Sistemleri Bölümü \\
\hline $\mathbf{4}$ & Jeofizik Mühendisliği Bölümü & $\mathbf{1 2}$ & Sosyoloji Bölümü \\
\hline $\mathbf{5}$ & İnşaat Mühendisliği Bölümü & $\mathbf{1 3}$ & Psikoloji Bölümü \\
\hline $\mathbf{6}$ & Harita Mühendisliği Bölümü & $\mathbf{1 4}$ & Radyo, Televizyon ve Sinema Bölümü \\
\hline $\mathbf{7}$ & İşletme Bölümü & $\mathbf{1 5}$ & Mülkiyet Koruma ve Güvenlik Bölümü \\
\hline $\mathbf{8}$ & Maliye Bölümü & $\mathbf{1 6}$ & İlk ve Acil Yardım Bölümü \\
\hline
\end{tabular}

\subsection{Araştırmanın Amacı}

Bu çalışmada Gümüşhane Üniversitesi hedef olarak belirlenen bölüm başkanlarının acil durum ve afetlere karşı risk algılarının belirlenmesi amaçlanmıştır. Gümüşhane Üniversitesi'nde, faaliyet alanı açısından bünyesinde acil durum ve afetlerde öncesinde, sırasında veya sonrasında müdahaleleri barındıran afet yönetim sürecinde rol alacak paydaşların risk algılarını değerlendirmek amacıyla gerçekleştirilen, betimsel bir çalışmadır.

\subsection{Araştırmanın Evreni ve Örneklemi}

Bu araştırmada, Gümüşhane Üniversitesi'nde Afet Yönetim Sürecinde Rol Alacak paydaşlardan 16 bölüm koordinatörleri risk algıları değerlendirilmiştir. Ayrıca araştırmaya dâhil edilen bölüm başkanlarının afet yönetim sürecinde aktif faaliyet gösteren Akademik alanlardan olması tercih edilmiştir.

\subsection{Araştırmanın Modeli}

Çalışma kapsamında oluşturulmuş derinlemesine mülakat formu alınan izinler doğrultusunda çalışmanın örneklem grubuna uygulanmıştır. 13 tema belirlenerek araştırma modeli araştırmacılar tarafından oluşturulmuştur. 


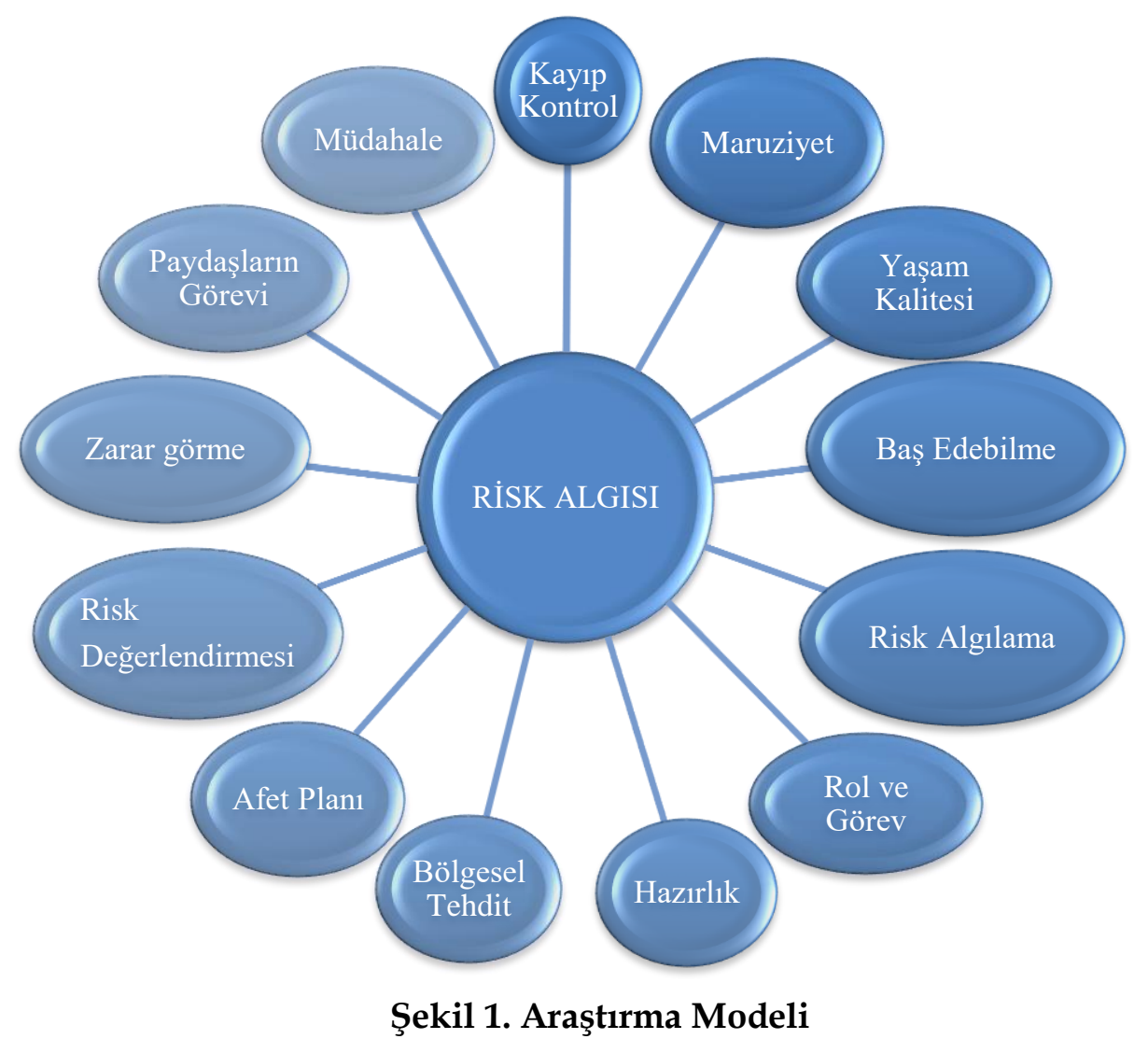

\section{Bulgular ve Tartışma}

Çalışma, temalar değerlendirilip alt kategorilere ayrılmıştır (Tablo 2).

Tablo 2. Genel Temalar ve Terminolojik Bilgi Değerlendiren Temalar

\begin{tabular}{|c|c|}
\hline \multirow{13}{*}{$\begin{array}{l}\text { Risk Algısı Durumuna } \\
\text { İlişkin Genel Temalar }\end{array}$} & Kayıp Kontrol Durumuna İlişkin Temalar \\
\hline & Maruziyet Yaşama Durumuna İlişkin Temalar \\
\hline & Tehditlerin Yaşam Kalitesine Etkisini Değerlendiren Temalar \\
\hline & Baş Edebilme Kapasitesi, Stratejisine İlişkin Temalar \\
\hline & Risk Algılama Etmenlerine İlişkin Temalar \\
\hline & Rol ve Görev Durumuna İlişkin Temalar \\
\hline & Hazırlık Durumuna İlişkin Temalar \\
\hline & Bölgesel Tehdit Durumuna İlişkin Temalar \\
\hline & Afet Planına İlişkin Temalar \\
\hline & Risk Değerlendirme Periyoduna İlişkin Temalar \\
\hline & Müdahale Çabasına İlişkin Temalar \\
\hline & Paydaşların Görev Durumuna İlişkin Temalar \\
\hline & Zarar Görme/Tehdit İlişkin Temalar \\
\hline
\end{tabular}

Çalışma kapsamında "risk algısı teması" 5 farklı alt boyutta sınıflanmıştır. Katılımcıların risk algıları güvensizlik $(n=9)$, potansiyel kayıp $(n=9)$ ve zarar görme $(n=8)$ üzerinde yoğunlaşmaktadır (Tablo 3).

Tablo 3. Risk Algısı Durumuna İlişkin Temalar

\begin{tabular}{|l|l|l|}
\hline \multirow{2}{*}{} & Tema & $\mathbf{n}$ \\
\cline { 2 - 3 } & Güvensizlik & 9 \\
\cline { 2 - 3 } & Zarar Görmek & 8 \\
\hline
\end{tabular}




\begin{tabular}{|l|l|l|} 
Risk Algısı & Potansiyel Kayıp & 9 \\
\cline { 2 - 3 } & Tehlike Kaynağı & 7 \\
\cline { 2 - 3 } & Hizmet Aksaması & 6
\end{tabular}

Çalışma kapsamında risk algılarında "kayıp kontrol" teması 3 farklı alt boyutta sınıflandırılmıştır. Katılımcıların 10 tanesi evet, 5 tanesi kısmen 1 tanesi hayır cevabını vermiştir. Temada kullanılan kavramlar sıklıklarına göre sıralandığında; Ekip Uyumu 14, Bilgi 8, Planlama 6, Tatbikat 3, Tecrübe 2 katılımcı kayıpların kontrol edilebileceğini düşünmektedir. Katılımcılar ekip uyumu, bilgi, planlama, tatbikat, tecrübe ile afet kayıplarının kontrol edilebileceği düşünülmektedir (Tablo 4).

Katılımcl Cevaplarn:

"... yapılar kurallara uygun bir şekilde inşa edilirse, koordineli çalışma olursa, tatbikat yapılırsa, bilgilendirme yapılırsa, heyelanlı bölgeye yerleşim yeri yapılmazsa kayıplar kontrol altına alınabilir..."

Tablo 4. Kayıp Kontrol Durumuna İlişkin Temalar

\begin{tabular}{|l|l|l|l|}
\hline & Tema & $\mathbf{n}$ \\
\cline { 2 - 4 } & \multirow{4}{*}{ Kayı Kontrol } & Tatbikat & 3 \\
\cline { 3 - 4 } & & Planlama & 6 \\
\cline { 3 - 4 } & Ekip uyumu & 14 \\
\cline { 3 - 4 } & Bilgi & 8 \\
\cline { 3 - 4 } & Tecrübe & 2 \\
\cline { 2 - 4 } & & 1 \\
\cline { 2 - 4 } & Hayır & & 5 \\
\cline { 2 - 4 } & Kismen & & \\
\hline
\end{tabular}

Çalışmada "maruziyet yaşamayanlar" teması 2 farklı alt boyutta sınıflanmıştır. Maruziyet yaşamayan katılımcılar içerisinden 2 kişinin kendisi ve çevresinin herhangi bir afete maruz kalmadığı görülmektedir. Temalarda kullanılan kavramlar sıklıklarına göre incelendiğinde: Kendisi ile beraber çevresi maruziyet yaşayan 4 katılımcıdan 3'ünün Depremi, 1'inin Kaya Düssmesini, 1'inin Trafik Kazasını, 1'inin Yapı Çökmesini ve 1'inin de Heyelanı tecrübe ettiği görülmektedir (Tablo 5).

Tablo 5. Maruziyet Yaşama Durumuna İlişkin Temalar

\begin{tabular}{|c|c|c|c|c|}
\hline \multirow{7}{*}{$\begin{array}{c}\text { Maruziyet } \\
\text { Yaşamayanlar }\end{array}$} & Tema & $\bar{n}$ & & $\mathbf{n}$ \\
\hline & \multirow{5}{*}{$\begin{array}{c}\text { Kendisi ve çevresi } \\
\text { yaşayan }\end{array}$} & \multirow{5}{*}{4} & Yapı çökmesi & 1 \\
\hline & & & Deprem & 3 \\
\hline & & & Kaya düşmesi & 1 \\
\hline & & & Trafik kazası & 1 \\
\hline & & & Heyelan & 1 \\
\hline & $\begin{array}{c}\text { Kendisi ve çevresi } \\
\text { yaşamayan }\end{array}$ & 2 & & 2 \\
\hline
\end{tabular}

"Maruziyet yaşayanlar" teması ise; 6 farklı alt boyutta sınıflanmıştır. Temalarda kullanılan kavramlar sıklıklarına göre sıralandığında: 10 katılımcıdan 5'i Sel, 4'ü Deprem, 4'ü Kaya Düşmesi, 3'ü Heyelan, 1'i Çı̆̆, 1'i Yapı Çökmesi gibi afetlerine maruz kalmıştır. Maruziyet yaşayan kişiler tarafından değerlendirildiğinde yoğunluğun bölgesel afetlerden olan sel, kaya düşmesi ve heyelan üzerinde yoğunlaştığı görülmektedir (Tablo 6).

Katılima Cevaplarn:

"...kaya düşmesi, istinat duvarının çökmesi, deprem, çı̆̆, taşkın, toprak kayması, trafik kazası maruziyeti yaşadım..." 
Tablo 6. Maruziyet Yaşayanların Durumuna İlişkin Temalar

\begin{tabular}{|c|l|c|}
\hline \multirow{5}{*}{ Maruziyet Yaşayanlar } & Tema & $\mathbf{n}$ \\
\cline { 2 - 3 } & Çı̆ & 1 \\
\cline { 2 - 3 } & Kaya düşmesi & 4 \\
\cline { 2 - 3 } & Yapı çökmesi & 1 \\
\cline { 2 - 3 } & Sel & 5 \\
\cline { 2 - 3 } & Deprem & 4 \\
\cline { 2 - 3 } & Heyelan & 3 \\
\hline
\end{tabular}

Katılımcıların risk algıları "tehditlerin yaşam kalitesine etkisi" teması ile 9 farklı alt boyutta sinıflanmıştır. Temalar kullanılan kavramlar sıklıklarına göre incelendiğinde; yoğunluğun psikolojik etkilerde olduğu görülmektedir (Tablo 7).

Katılımor Cevaplarn:

"...hayatımı yok etme, psikolojik etkiler-uyku problemi, kötü alışkanliklar edinme, aile hayatının zarar görmesi, eğitim mahrumiyeti, ekonomik kayıp, can kaybı, ölüm, yangın, güvensiz yaşam, yaşam kalitesinin düşmesi gibi olumsuz etkilerle karşılaşırız..."

\section{Tablo 7. Tehditlerin Yaşam Kalitesine Etkisini Değerlendiren Temalar}

\begin{tabular}{|c|c|c|}
\hline \multirow{10}{*}{$\begin{array}{c}\text { Tehditlerin Yaşam } \\
\text { Kalitesine Etkisi }\end{array}$} & Tema & $\mathbf{n}$ \\
\hline & Güvenlik & 3 \\
\hline & Psikolojik & 10 \\
\hline & Ekonomik & 8 \\
\hline & Sosyolojik & 7 \\
\hline & Baş Etme Gücü & 1 \\
\hline & Ekolojik, Çevresel & 3 \\
\hline & Kamusal & 4 \\
\hline & Fiziksel & 8 \\
\hline & Etkisi Olmadığını Düşünen & 2 \\
\hline
\end{tabular}

"Baş edebilme kapasitesi, stratejisi" teması ise; 10 farklı alt boyutta sinıflanmıştır. Temada kullanılan baş edebilme kapasitesini etkileyen kavramlardan denetim $(n=12)$ ve teknoloji $(n=11)$ en sık karşımıza çıkan faktörlerdir (Tablo 8).

Katılimcr Cevaplarn:

"...dayanıklı yapı tasarımı, denetim, bilinçlendirme, binaların sağlamlaştırılması, önlem alma çalışmaları stratejileri geliştirilmelidir..."

Tablo 8. Baş Edebilme Kapasitesi, Stratejisine İlişkin Temalar

\begin{tabular}{|l|l|c|}
\hline \multirow{2}{*}{} & Tema & $\mathbf{n}$ \\
\cline { 2 - 3 } & Güven & 3 \\
\cline { 2 - 3 } & Beklenti & 7 \\
\cline { 2 - 3 } & İş Ahlakı & 1 \\
\cline { 2 - 3 } & Denetim & 12 \\
\cline { 2 - 3 } & Yetersiz Önleme Çalışması & 10 \\
\hline
\end{tabular}




\begin{tabular}{|l|l|c|}
\hline $\begin{array}{l}\text { Baş Edebilme Kapasitesi, } \\
\text { Stratejisi }\end{array}$ & Teknoloji & 11 \\
\cline { 2 - 3 } & Stratejinin Olmaması & 10 \\
\cline { 2 - 3 } & Teknik Personel Yetersizliği & 4 \\
\cline { 2 - 3 } & Ekolojik Dengenin Bozulması & 7 \\
\cline { 2 - 3 } & Hazırlık Çalışmasının Olmaması & 7 \\
\hline
\end{tabular}

Katılımcıların "risk algılama etmenleri" teması 10 farklı alt boyutta sınıflanmıştır. Temalar kullanılan kavramların sıklıklarına göre incelendiğinde; geçmiş afetsellik $(n=10)$, bilinç $(n=9)$ ve tehlikeleri algılama $(n=8)$ en fazla verilen cevaplardandır (Tablo 9).

Katılımci Cevaplarn:

"...deneyim, çalışmalar yapmak, bilinç oluşturmak, să̆lam yapı oluşturarak, eğitim ile, tatbikat yaparak, tedbirli davranış sergileyerek riskleri algılayabiliriz..."

Tablo 9. Risk Algılama Etmenlerine İlişkin Temalar

\begin{tabular}{|l|l|c|}
\hline \multirow{4}{*}{ Risk Algılama } & Tema & $\mathbf{n}$ \\
\cline { 2 - 3 } & Kültür & 4 \\
\cline { 2 - 3 } & Hareket Kabiliyeti & 6 \\
\cline { 2 - 3 } & Muallaklık & 2 \\
\cline { 2 - 3 } & Bilinç & 9 \\
\cline { 2 - 3 } & Hazırlık Algısı & 6 \\
\cline { 2 - 3 } & Kurumsal Öğreti & 10 \\
\cline { 2 - 3 } & Geçmiş Afetsellik & 5 \\
\cline { 2 - 3 } & Tecrübe/Deneyim & 8 \\
\cline { 2 - 3 } & Tehlikeleri Algılama & 5 \\
\hline
\end{tabular}

Çalışma kapsamında risk algısına göre "bölgesel tehdit" teması 5 farklı alt boyutta sınıflanmıştır. Kullanılan kavramlar sıklıklarına göre incelendiğinde; çevresel $(n=11)$ ve alt yapısal $(\mathrm{n}=10)$ tehditler ön plana çıkmaktadır (Tablo 10).

Tablo 10. Bölgesel Tehdit Durumuna İlişkin Temalar

\begin{tabular}{|l|l|c|}
\hline \multirow{4}{*}{ Bölgesel Tehdit } & Tema & $\mathbf{n}$ \\
\cline { 2 - 3 } & Alt yapı & 10 \\
\cline { 2 - 3 } & Fiziksel & 5 \\
\cline { 2 - 3 } & Sosyal & 8 \\
\cline { 2 - 3 } & Ekonomik & 8 \\
\cline { 2 - 3 } & Çevresel & 11 \\
\hline
\end{tabular}

Risk algılarına bağlı olarak "hazırlık" teması 6 farklı alt boyutta sınıflanmıştır. Hazırlık teması için en fazla kullanılan kavram eğitim $(n=8)$ olmuştur (Tablo 11). 


\section{Tablo 11. Hazırlık Durumuna İlişkin Temalar}

\begin{tabular}{|c|l|l|c|}
\hline & Tema & $\mathbf{n}$ \\
\cline { 3 - 4 } & \multirow{3}{*}{ Hazırlık } & Yapısal & 2 \\
\cline { 3 - 4 } & Evet & Tatbikat & 3 \\
\cline { 3 - 4 } & Yönetmeliğe uygunluk & 3 \\
\cline { 3 - 4 } & Uzak durmak & 1 \\
\cline { 3 - 4 } & & Eğitim & 3 \\
\cline { 3 - 4 } & Erken algılama ve uyarı & 7 \\
\hline
\end{tabular}

Çalışma kapsamında "ailelerinin afetlere karşı hazırlıklı olma durumu" teması ile 4 farklı alt boyutta sınıflandırılmıştır. Temalarda kullanılan kavramlar sıklıklarına göre incelendiğinde: Eğitim 7, Korunma İç Güdüsü 7, Uzmanlık Alanından Dolayı 3, Tatbikat 2 olarak belirlenmiştir. Katılımcıların ailelerinin hazırlıklı olması kapsamında korunma iç güdüsü ve eğitim belirleyici etmen olmuştur (Tablo 12).

Katılımc1 Cevapları:

"...eğitim yetersizliği duyarsızlaştı̆̆ımızdan dolayı, tedbir alınmadığından dolayı, uygulama yetersizliği, kadercilik anlayışından dolayısı algılama dürtüsüne sahip değiller..."

\section{Tablo 12. Ailelerinin Afetlere Karşı Hazırlıklı Olma Durumuna İlişkin Temalar}

\begin{tabular}{|c|l|l|}
\hline \multirow{3}{*}{$\begin{array}{c}\text { Ailelerinin Afetlere Karşı } \\
\text { Hazılıklı Olma Durumuna } \\
\text { İlişkin Temalar }\end{array}$} & Tema & $\mathbf{n}$ \\
\cline { 2 - 3 } & Uzmanlık alanından dolayı & 3 \\
\cline { 2 - 3 } & Tatbikat & 2 \\
\cline { 2 - 3 } & Eğitim & 7 \\
\cline { 2 - 3 } & Korunma iç güdüsü & 7 \\
\hline
\end{tabular}

"Ailelerinin afetlere karşı hazırlıklı olmama durumu" teması ise; 5 farklı alt boyutta sınıflandırılmıştır. Temalarda kullanılan kavramlar sıklıklarına göre incelendiğinde: Önlem alınmaması 5, Tehlike/Risk Bilinç Düzeyi 5, Farkındalık 4, Kadercilik 4, Donanımsızlık olarak belirlenmiştir. Katılımcıların ailelerinin afete hazır olmaması durumu kişilerin risk algılarının oluşmaması ve risk algılarını bilmemelerinden kaynaklanabilir (Tablo 13).

\section{Tablo 13. Ailelerinin Afetlere Karşı Hazırlıklı Olmamasına İlişkin Temalar}

\begin{tabular}{|c|l|l|}
\hline \multirow{4}{*}{$\begin{array}{c}\text { Ailelerinin Afetlere Karşı } \\
\text { Hazırlıklı Olmamasına İlişkin } \begin{array}{c}\text { Oling } \\
\text { Temalar }\end{array}\end{array}$} & Tema & $\mathbf{n}$ \\
\cline { 2 - 3 } & Tehlike/ Risk bilinç düzeyi & 5 \\
\cline { 2 - 3 } & Karkındalık & 4 \\
\cline { 2 - 3 } & Kadercilik & 4 \\
\cline { 2 - 3 } & Önlem alınmaması & 5 \\
\cline { 2 - 3 } & Donanımsılık & 3 \\
\hline
\end{tabular}

Çalışma kapsamında "afet planı" teması 6 farklı alt boyutta sınıflanmıştır. Temalarda kullanılan kavramlar sıklıklarına göre değerlendirildiğinde: Görünürlük/Erişe bilirlik 8, Hukuki Zorunluluk 5, Uzman Danışmanlık 5, Bilmiyor 5, Yapıyor 5, Eğitim 4 olarak sıralanmıştır (Tablo 14).

Tablo 14. Afet Planına İlişkin Temalar

\begin{tabular}{|l|l|c|}
\hline \multirow{4}{*}{ Afet Planı } & Tema & $\mathbf{n}$ \\
\cline { 2 - 3 } & Eğitim & 4 \\
\cline { 2 - 3 } & Hukuki zorunluluk & 5 \\
\cline { 2 - 3 } & Uzman Danışmanlık & 5 \\
\cline { 2 - 3 } & Görünürlük/Erişe bilirlik & 8 \\
\cline { 2 - 3 } & Bilmiyor & 5 \\
\cline { 2 - 3 } & Yapıyor & 5 \\
\hline
\end{tabular}


Katılımcıların verdikleri cevaplar doğrultusunda "afet planı tasarımı" teması 9 farklı alt boyutta sınıflandırılmıştır. Katılımcılardan 6'sı plan tasarımına dâhil olmayı düşünmediğini ifade etmiştir. 10 katılımcının yanıtlarına göre plan tasarımında yoğunluğun tatbikat $(n=5)$ ve yapı güvenliği $(n=5)$ yanitlarından olduğu görülmüştür (Tablo 15).

Katılima Cevaplarn:

"...eğitim, eşyaları sabitleyip saklanma yerleri belirlemek, deprem anında binaların boşaltılması, afete yönelik proje geliştirdim, daha güvenli yerleri yerleşim alanı olarak seçiyorum, acil durum eylem planı hazırlıyoruz, tahliye, zarar azaltma çalışmaları, erken uyar sistemleri gibi planlar yapıyoruz..."

Tablo 15. Plan Tasarımına İlişkin Temalar

\begin{tabular}{|l|l|c|}
\hline \multirow{4}{*}{ Plan Tasarımı } & Tema & $\mathbf{n}$ \\
\cline { 2 - 3 } & Tatbikat & 5 \\
\cline { 2 - 3 } & Eğitim & 3 \\
\cline { 2 - 3 } & Akademik Çalışma & 3 \\
\cline { 2 - 3 } & Sı̆̆ınak & 2 \\
\cline { 2 - 3 } & Zarar Azaltma & 2 \\
\cline { 2 - 3 } & Tahliye Farkındalı̆̆ & 3 \\
\cline { 2 - 3 } & Yapı Güvenliği & 6 \\
\cline { 2 - 3 } & Erken Uyarı Sistemi & 6 \\
\cline { 2 - 3 } & Düşünmüyorum & \\
\hline
\end{tabular}

Çalışma kapsamında "risk değerlendirme" periyodu teması 6 farklı alt boyutta sınıflanmıştır. Temalar kullanılan kavramlar sıklıklarına göre incelendiğinde: Sürekli 9, Hiç 7, Öncelik 6, Zorunluluk 6, Eğitim 3, Sorumluluk 2 olarak sıralanmıştır (Tablo 16).

Katılimci Cevaplarn:

"...yapının uygun inşa edildiğini düşünerek, uzmanlara güvenip sigorta yaptırarak, kurumda mevcut risk değerlendirmesi olduğunu düşünerek risk değerlendirmesi yapmadık..."

Tablo 16. Risk Değerlendirme Periyoduna İlişkin Temalar

\begin{tabular}{|c|l|c|}
\hline \multirow{4}{*}{$\begin{array}{c}\text { Risk } \\
\text { Değerlendirme } \\
\text { Periyodu }\end{array}$} & Tema & $\mathbf{n}$ \\
\cline { 2 - 3 } & Sürekli & 9 \\
\cline { 2 - 3 } & Öncelik & 6 \\
\cline { 2 - 3 } & Zorunluluk & 6 \\
\cline { 2 - 3 } & Ĕgitim & 3 \\
\cline { 2 - 3 } & Sorumluluk & 2 \\
\cline { 2 - 3 } & Hiç & 7 \\
\hline
\end{tabular}

Katılımcıların verdikleri yanıtlar doğrultusunda "paydaşların görevi" teması 10 farklı alt boyutta sınıflandırılmıştır. Paydaşlara düşen görevler incelendiğinde, verilen yanıtlar uzman desteği (n=13), kurum desteği $(n=12)$ ve tatbikat $(n=12)$ üzerinde yoğunlaşmaktadır (Tablo 17).

Tablo 17. Paydaşların Görev Durumuna İlişkin Temalar

\begin{tabular}{|l|c|}
\hline Tema & $\mathbf{n}$ \\
\hline Eğitim Materyali & 9 \\
\hline Uzman Desteği & 13 \\
\hline Koordinasyon & 8 \\
\hline
\end{tabular}




\begin{tabular}{|c|l|r|}
\hline \multirow{4}{*}{$\begin{array}{c}\text { Paydaşların } \\
\text { Görevi }\end{array}$} & Kurum Desteği & 12 \\
\cline { 2 - 3 } & Davranış Değişikliği & 7 \\
\cline { 2 - 3 } & Tatbikat & 12 \\
\cline { 2 - 3 } & Mevcut Durum Değerlendirmesi & 11 \\
\cline { 2 - 3 } & Uygulama & 10 \\
\cline { 2 - 3 } & Riske Göre Önlem & 8 \\
\cline { 2 - 3 } & Bütünleşik Bir Plan & 6 \\
\hline
\end{tabular}

Çalışma kapsamında "kampüs plan görevlendirme" teması farklı alt boyutta sınıflandırılmıştır. Temalarda kullanılan kavramlar sıklıklarına göre incelendiğinde: Bilgim Yok 9, İdari Personel 5, Öğrenci 3, Akademisyen 2 kez kullanılmıştır. Katılımcıların çoğunun kampüs plan görevlendirmelerinden bilgisi olmadığı saptanmakta olup, bilgisi olanlarında çoğunluğu da görevlendirmelerin idari personeller tarafından yapılacağını düşünmektedir (Tablo 18).

Tablo 18. Kampüs Plan Görevlendirmesine İlișkin Temalar

\begin{tabular}{|c|l|c|}
\hline \multirow{4}{*}{$\begin{array}{c}\text { Kampüs İçi } \\
\text { Görevlendirme }\end{array}$} & Tema & $\mathbf{n}$ \\
\cline { 2 - 3 } & Akademisyen & 2 \\
\cline { 2 - 3 } & Öğrenci & 3 \\
\cline { 2 - 3 } & İdari personel & 5 \\
\cline { 2 - 3 } & Bilgim yok & 9 \\
\hline
\end{tabular}

Paydaşların afet ve acil durum planlarının "yeterliliği" teması 3 farklı boyutta, sınıflandırılmıştır. Temalarda kullanılan kavramlar sıklıklarına göre incelendiğinde: Eğitim Yetersiz 7, Bilgisizlik 5, Tatbikat Yetersizliği 3 olarak saptanmıştır. Katılımcılar, planların yeterliliği konusunda yetersiz bilgiye sahip olduklarını söylemiştir (Tablo 19).

Katılımal Cevaplan:

“...davranış değişikliği, bilinç eksikliği, duyarsızlık, eğitim, bilgi ve bilinç düzeyinin arttırılması, kurum desteği, maddi yetersizliklerden dolayı hazırlı̆ımız yetersizdir..."

Tablo 19. Yeterlilik Durumuna İlişkin Temalar

\begin{tabular}{|l|l|l|}
\hline \multirow{4}{*}{ Yeterlilik } & Tema & $\mathbf{n}$ \\
\cline { 2 - 3 } & Tatbikat yetersizliği & 3 \\
\cline { 2 - 3 } & Eğitim yetersiz & 7 \\
\cline { 2 - 3 } & Bilgisizlik & 5 \\
\hline
\end{tabular}

Afet paydaşlarının "müdahale çabası" teması ise 5 farklı alt boyutta sınıflandırılmıştır. Temalarda kullanılan kavramlar sıklıklarına göre incelendiğinde: Bilgisi Olmayanlar 9, Uzmanlar Yapsın diyenler 5, Olay Olmadan Önleme 4, Tatbikat/uygulama 2, Takım Çalışması 1 olarak belirlenmiştir. Katılımcıların çoğunluğunun müdahale çabalarından bilgisi yoktur ve bilgisi olanların çoğunluğu da müdahale çabalarının bir uzmanlık tarafından gerçekleştirilmesini beklemektedir (Tablo 20).

Katılımal Cevapları:

"...uzman kişilerin bilgisine gereksinim, takım çalışması yapacak ekip mevcut, tatbikatlar, bilgimiz mevcut değil, önleyici çalı̧̧maların yapılması..."

Tablo 20. Müdahale Çabasına İlişkin Temalar

\begin{tabular}{|l|l|c|}
\hline \multirow{2}{*}{} & Tema & $\mathbf{n}$ \\
\cline { 2 - 3 } & Tatbikat/Uygulama & 2 \\
\hline
\end{tabular}




\begin{tabular}{|l|l|c|}
\hline \multirow{4}{*}{$\begin{array}{c}\text { Müdahale } \\
\text { Çabası }\end{array}$} & Olay Olmadan Önleme & 4 \\
\cline { 2 - 3 } & Uzmanlar Yapsın diyenler & 5 \\
\cline { 2 - 3 } & Bilgisi Olmayanlar & 9 \\
\cline { 2 - 3 } & Takım Çalışması & 1 \\
\hline
\end{tabular}

Afet paydaşlarının verdikleri yanıtlar doğrultusunda afet öncesi, sırası ve sonrasında ki "rol ve görevleri" 5 farklı alt boyutta sinıflandırılmıştır. Temalarda kullanılan kavramlar sıklıklarına göre: Uzman Olarak Görev Alma 8, Bilgilendirme/ Bilinçlendirme 9, İyileştirme 9, Tedbir Önlem 7, Bilgi Yönetimi/ iletişim 4 olarak belirlenmiştir. Katılımcıların afette ki rol ve görevlerinin çoğunluğu afet öncesi bilgilendirme ve afet sonrası iyileştirme çalışmalarında yer aldıklarını belirtmektedir (Tablo 21).

Katılımal Cevaplarn:

“... Afet öncesi: risk haritalarınn oluşturulması, depo alanlarmın önceden belirlenmesi, transfer güzergahlarmın önceden belirlenmesi, çadır kent ve toplanma alanlarının belirlenmesi, afet bilincinin oluşturulması, halkı bilinçlendirme,

Afet sırasi: oluşabilecek yol tıkanmalarının güzergahlarnın belirlenmesi ve coğrafi olarak izlenmesi, kurtarma ekiplerinin sev ve idaresi, enerjilerin kesilip verilmesi, bilgi yönetimi, yangın güvenliği să̆lama, lojistik destek, finans kaynaklarının yönetilmesi, arama kurtarma çalışmalarım yapmak,

Afet sonrasi: afet sorasi kayılarm tespiti, yeniden planlanmasi ve organizasyonu, durum değerlendirilmesi, psiko-sosyal müdahale görev ve sorumluluklarımızdır..."

Tablo 21. Rol ve Görev Durumuna İlişkin Temalar

\begin{tabular}{|l|l|c|}
\hline \multirow{4}{*}{ Rol ve Görev } & Tema & $\mathbf{n}$ \\
\cline { 2 - 3 } & Bilgi Yönetimi/ Illetişim & 4 \\
\cline { 2 - 3 } & Tedbir Önlem & 7 \\
\cline { 2 - 3 } & İyileştirme & 9 \\
\cline { 2 - 3 } & Bilgilendirme/Bilinçlendirme & 8 \\
\cline { 2 - 3 } & Uzman Olarak Görev Alma & \\
\hline
\end{tabular}

Paydaşların "Zarar Görme/ Tehdit" ilişkin teması farklı alt boyutlarda sınıflandırılmıştır. Paydaşların "deprem" teması için verdikleri yanıtlar 7 farklı alt boyutta sınıflanmıştır. Temalar kullanılan kavramlar sıklıklarına göre incelendiğinde: Zarar/Yıkım 8, Tektonik Hareket 8, Yer Sarsıntısı 6, Enerji Boşalması 2, Yapı Çökmesi 2, Teknolojik İlerleme 2, Gerilme 1 olarak sıralanmıştır (Tablo 22).

Katılımal Cevaplarn:

"...Deprem: Yeryüzünde yaşadığımız sarsıntılar, tektonik hareketler sonucu fayların kırılması, yer kabuğundaki kırıklarda oluşan enerji boşalımı, jeolojik sarsıntı olarak algılıyorum..."

Tablo 22. Deprem Kavramsal Algısına İlişkin Temalar

\begin{tabular}{|l|l|c|}
\hline \multirow{4}{*}{ Deprem } & Tema & $\mathbf{n}$ \\
\cline { 2 - 3 } & Enerji boşalması & 2 \\
\cline { 2 - 3 } & Gerilme & 1 \\
\cline { 2 - 3 } & Teknolojik ilerleme & 2 \\
\cline { 2 - 3 } & Zarar/yıkım & 8 \\
\cline { 2 - 3 } & Yer sarsıntısı & 6 \\
\cline { 2 - 3 } & Tektonik hareket & 8 \\
\cline { 2 - 3 } & Yapı çökmesi & 2 \\
\hline
\end{tabular}


Çalışma kapsamında "heyelan" teması ise 5 farklı alt boyutta sınıflanmıştır. Temalar kullanılan kavramlar sıklıklarına göre incelendiğinde: Toprak Hareketi 6, Eğim 5, Çevresel Bozulma 4, Zarar 4, Yağış 2 olarak sıralanmıştır (Tablo 23).

Katılımal Cevaplarn:

"...Heyelan: Bitki örtüsünün, eğimin veya insan müdahalesinin etkisi ile zeminin taşınması, durabilitesini kaybeden toprağın harekete geçmesi ve buna yağışın sebep olması, belli bir eğim dahilinde toprak hareketi olarak algiliyorum..."

Tablo 23. Heyelan Kavramsal Algısına İlişkin Temalar

\begin{tabular}{|l|l|c|}
\hline \multirow{4}{*}{ Heyelan } & Tema & n \\
\cline { 2 - 3 } & Çevresel bozulma & 4 \\
\cline { 2 - 3 } & Eğim & 5 \\
\cline { 2 - 3 } & Toprak hareketi & 6 \\
\cline { 2 - 3 } & Zarar & 4 \\
\cline { 2 - 3 } & Yağış & 2 \\
\hline
\end{tabular}

Verilen yanıtlar doğrultusunda "kaya düşmesi" teması 7 farklı alt boyutta sinıflanmıştır. Temalar kullanılan kavramlar sıklıklarına göre incelendiğinde: Yüksek Yerden Hareket 5, Bozulma 5, Yer Çekimi 4, Coğrafya/Topoğrafya 4, Ölüm/Zarar 4, Soğuk Sıcak Farkı 2, Yağış 1 olarak siralanmiştır (Tablo 24).

Katılima Cevaplart:

“...Kaya düşmesi: Taş parçalarının koparak bütününden kopmasl, sıcak soğuk iklim değgişikliğinin artması sonucu yer çekiminin etkisi ile yapmış olduğu hareket, kayanın yüksek yerden yere doğru düşmesi olarak algilıyorum..."

Tablo 24. Kaya Düşmesi Kavramsal Algısına İlişkin Temalar

\begin{tabular}{|l|l|c|}
\hline \multirow{4}{*}{ Kaya Düşmesi } & Tema & $\mathbf{n}$ \\
\cline { 2 - 3 } & Bozulma & 5 \\
\cline { 2 - 3 } & Yüksek yerden hareket & 5 \\
\cline { 2 - 3 } & Soğuk sıcak fark1 & 2 \\
\cline { 2 - 3 } & Yağış & 1 \\
\cline { 2 - 3 } & Yer çekimi & 4 \\
\cline { 2 - 3 } & Coğrafya/topoğrafya & 4 \\
\cline { 2 - 3 } & Ölüm/zarar & 4 \\
\hline
\end{tabular}

Çalışma kapsamında "sel" teması ile de 7 farklı alt boyutta sınıflanmıştır ve temalar kullanılan kavramlar, sıklıklarına göre incelendiğinde: Yağış Miktarındaki Artış 8, Zarar 7, Yerel

Yanlışlık/Yanlış Yapılaşma 5, Yoğun Su Taşması 5, Yetersiz Drenaj 4, Usulsüz Doğa Kullanımı 4, Dere Yatağ 1 Daralması 3 olarak sıralanmıştır (Tablo 25).

Katılımal Cevaplarn:

“...Sel: Dere yatağının taşması sonucu muhitlerin su altında kalması, suyun belli bir debinin üstüne çıkması, aşrı yağıştan sonra taşkın olarak harekete geçen su kütlesi, büyük çaplı su baskınları, gökyüzündeki suların taşması..."

Tablo 25. Sel Kavramsal Algısına İlişkin Temalar

\begin{tabular}{|l|l|l|}
\hline \multirow{5}{*}{ Sel } & Tema & n \\
\cline { 2 - 3 } & Zarar & 7 \\
\cline { 2 - 3 } & Yetersiz drenaj & 4 \\
\cline { 2 - 3 } & Yerel yanlışlık/yanlış yapılaşma & 5 \\
\cline { 2 - 3 } & Usulsüz doğa kullanımı & 4 \\
\cline { 2 - 3 } & Yağış miktarındaki artış & 8 \\
\cline { 2 - 3 } & Dere yatağı daralması & 3 \\
\cline { 2 - 3 } & Yoğun su taşması & 5 \\
\hline
\end{tabular}


Avrupa Birliği tarafından desteklenen “Risk Algısı ve Doğal Tehlikeler" raporu 11-12 Mart 2010 tarihlerinde Haigerloch'ta düzenlenmiş olup Avrupa' daki doğal tehlikelerin algılanmasına ilişkin vaka incelemeleri ile gerçekleştirilmiştir. Bu rapor sonuçlarına göre, sel riskinin algılanması, 2002'deki sel afetinde önemli ölçüde etkilediği gözlenmiştir. Selden yaklaşık üç buçuk yıl sonra algilanan sel riskinin, öncekinden daha fazla olduğu saptanmıştır (Wachinger vd., 2013: 1049-1062). Çalışmamızda da katılımcıların birçoğu afetlerin tekrar edebileceğini düşünmekte ve geçmişte yaşanan afetlerin tekrardan meydana gelme ihtimalini yüksek olarak değerlendirmektedir. 2015 yılı Pakistan'da, ülkedeki afet yönetimi üzerinde çalışan hükümet paydaşlarına ve afet yönetimi kurumlarına temel bilgiler sunmayı amaçlayan çalışmaya göre afet deneyimi ile risk algısı arasında anlamlı bir doğrusal ilişki olduğunu belirlemişlerdir. Bu sel deneyimi fazla olan kişilerin risk algısı düzeyinin daha yüksek olduğu anlamına gelmektedir. Ayrıca eğitim seviyesi ve toplulukların bilgi düzeyi de algılanan riski doğrudan etkilediği belirlenmiştir (Khan vd., 2017: 87-92). Çalışma evreni eğitim seviyesi doktora düzeyinde olan ve lisans düzeyinde eğitim sağlayan Akademik birimlerin koordinatörleri olarak belirlenmiştir.

18-24 yaş arasındaki lisans öğrencilerine uygulanan afete hazırlık davranışları, afet risk algıları, afete karşı inançlarının saptanmasını esas alan bir çalışmada; afete hazırlık konusunda ileri düzeyde bilgi sahibi olan katılımcıların, afetle karşılaşma konusunda risk algısının yüksek olduğu ve afete karşı hazırlık yapma tutumunda olduğu belirtilmiştir. Ayrıca yüksek öz-yeterlilik düzeyine sahip öğrencilerin, temel afet bilgileri düşük olan öğrencilere göre risk algılarının ve afet hazırlık seviyelerinin daha yüksek düzeye sahip olduğu belirlenmiştir (Goddard, 2017: 49). Çalışmamız kapsaminda bölümlerinde afetlere yönelik eğitim içeriklerine ve afetlerin hazırlık, zarar azaltma, müdahale ve iyileştirme aşamalarında çeşitli uzmanlık ve rollere sahip paydaşların risk algıları değerlendirildiğinde ise; plan yapma ve risk azaltma aşamalarında yapılan çalışmaların yetersiz olduğu sonucuna ulaşılmıştır. Katılımcıların çoğunluğu plan tasarımı aşamalarına dâhil olmayı düşünmemekte, kurumsal ve bireysel hazırlık ölçütlerini uzmanlara ve mevzuata bırakmaktadır. Toplum tabanlı afet yönetimi sistemlerinin yaygınlaştığı dünya ülkelerinden farklı olarak sorumluluk almaktan kaçınmaktadır.

\section{Sonuç ve Değerlendirme}

Katılımcı paydaşları en çok korkutan afet türünün deprem olduğu saptanmakla beraber bölgesel afet olarak, depremle karşılaşma risklerinin diğer risklere oranla düşük olduğu bilinmektedir. $\mathrm{Bu}$ da paydaşların bölgesel risklerden çok, genel risklerden korktuklarını göstermektedir. Yani kişilerin risk algıları, genel afetler üzerine kurgulanmıştır. Buradan hareketle paydaşların, bölgesel afet risklerinin farkında olmadıklarını söylememiz mümkün olup, en çok potansiyel kaybın yaşanacağı olguyu, deprem olarak gördükleri belirlenmiştir. Buna sebep olarak, katılımcı paydaşların etkin bir afet çalışması olmamasını söyleyebilir. Afet planı yapan katılımcıların, plan tasarlamadaki ana nedenlerinin; eğitim, sorumluluk, uzmanlık alanına girmesi, tatbikat yapması gibi nedenler olduğu saptanmıştır. Afet planı oluşturmayan katılımcıların ise; bilinç düzeyinin düşük olması, riskleri algılayamaması ya da kadercilik anlayışına sahip oldukları görülmüştür.

Afetlerde görev alacak katılımcı paydaşların görevleri değerlendirildiğinde; uzman desteği, kurum desteği, tatbikat ve uygulama alanları sonuçları saptanmıştır (Tablo 17). Yeterlilik durumlarına göre ele alındıklarında ise; eğitimin yetersizliği ve bilgi eksikliği ön plana çıkmaktadır (Tablo 19). Bunun da paydaşların içinde bulunduğu kampüs plan görevlendirmesindeki, sorumlu kişiler hakkında bilgi sahibi olmadıklarını söylemelerinin altında yatan etkenlerden biri olduğu söylenebilir. Paydaşların afet öncesinde, sırasında ve sonrasında birimlerdeki rol ve görevine baktığımız zaman; bilgi yönetişim, iletişim, tedbir-önlem alma, iyileştirme ve uzman olarak görev alma olmak üzere beş ana temada oluşmuştur. Buna karşın müdahale çabaları değerlendirildiğinde, bilgisi olmayan paydaşların yoğunlukta olduğu görülmektedir.

Afetler sebebiyle oluşabilmesi muhtemel kayıpların kontrol edebileceğini düşünen katılımcılar, yüksek oranda ekip uyumu, beraberinde bilgide artış ve planlama ile mümkün olabileceğini düşünmektedir. Yaşadığı bölgede afetlere maruz kalan katılımcılar ile maruziyet yaşamayan 
katılımcıları karşılaştırdığımızda ise maruziyet yaşayanların bölgenin mevcut tehlikelerini değerlendirebildiğini söylememiz mümkündür. Katılımcıların, yaşadığı bölgede herhangi bir afet meydana geldiğinde, yüksek oranda psikolojik olarak etkilenecekleri ve davranışlarında bozulmalar olacağı saptanmıştır. Ayrıca beraber ekonomik anlamda kayıp ve zarara uğrama, fiziksel anlamda zarar ve tehlikelerle karşılaşma ve sosyolojik açıdan genel olarak etkileneceğini düşünülmektedir.

Bu çalışma sonucunda önerilerimiz şu şekilde sıralanabilir:

- Kişilerin bölgesel afetlerin farkında olmaları sağlanmalı ve bunlara karşı önlem almaları teşvik edilmelidir,

- Müdahale ve koordine işlemlerinin uzman kişiler tarafından yapılması için üniversite kuruluşlarının kadrolarına, afetlerde uzman olan kişilerin dâhil edilmesi gerekmektedir,

- Mevcut hazırlığın eğitimle oluşabileceğini düşünülüp, eğitim müfredatlarında geçmiş afetlerin sosyal, ekonomik, fiziksel ve psikolojik etkileri irdelenerek var olan tehlikelere, zarar görebilirliğe ve risklere odaklanılmalıdır,

- Afetler insanların psikolojik, ekonomik, sosyolojik yaşam kalitesini düşebilmektedir. Afetlerle baş edebilme stratejisi geliştirilirken teknolojinin kullanımı artırılmalıdır,

- Risk alg1 düzeyini arttırmak adına afet bilinç arttırma çalışmalarının revize edilerek artırılmalıdır. Dirençliliğin artırılması için ise; üniversitelerin risk değerlendirilmelerini düzenli olarak revize etmeleri önerilmektedir.

\section{Kaynakça}

AFAD, Afet Yönetimi Terimler Sözlüğü. https://www.afad.gov.tr/aciklamali-afet-yonetimiterimleri-sozlugu, 2019.

Bang, H. N. (2009). Natural disaster risk, vulnerability and resettlement: relocation decisions following the lake Nyos and Monoum disasters in Cameroon (Doctoral dissertation, University of East Anglia).

Bayrak, T., Ulukavak, M., \& Acar, S. (2010). Gümüşhane Heyelanları, Harita Teknolojileri Elektronik Dergisi, 2(1), 1-12.

Cole, G. A., \& Withey, S. B. (1981). Perspectives on risk perceptions. Risk Analysis, 1(2), 143-163.

Crichton, D. (1999). The risk triangle. Natural disaster management, 102, 103.

Çakır, T. (2012). İtibar risklerinin yönetiminde risk iletişiminin rolü. Marmara İletişim Dergisi, (19), 94-111.

Fischhoff, B., Bostrom, A., \& Quadrel, M. J. (1993). Risk perception and communication. Annual review of public health, 14(1), 183-203.

Goddard, S. (2017). Disaster Preparedness Knowledge, Beliefs, Risk-Perceptions, and Mitigating Factors of Disaster Preparedness Behaviors of Undergraduate Students at a Large Midwest University. AT Still University of Health Sciences.

Kemp, R. V., Crawford, M. B., Pollard, S. J. T., Twigger-Ross, C., Fisher, J., and Weatherly, N., (2002) Strategic risk assessment: Phase II. Environment Agency R\&D Project E2-041

Khan, M. G., Johar, F., \& Baba, A. N. (2017). Disaster Management Risk Perception of Local Communities. Jurnal Kemanusiaan, 15(1).

Renn, O. (2008). Risk governance. Coping with uncertainty in a complex world. Earthscan, London.

Renn, O., \& Klinke, A. (2001). Environmental risks - perception, evaluation and management: epilogue. In Environmental risks: Perception, evaluation and management (pp. 275-299). Emerald Group Publishing Limited.

Rouyard, T., Kent, S., Baskerville, R., Leal, J., \& Gray, A. (2017). Perceptions of risks for diabetesrelated complications in Type 2 diabetes populations: a systematic review. Diabetic Medicine, 34(4), 467-477.

Thywissen, K. (2006). Components of risk: a comparative glossary. UNU-EHS.

Turan, M., Kaya, A. A., Oral, V. (2018). Küçük İşletmelerin Afet ve Acil Durumlara Yönelik Kurumsal Hazırlıklarının Değerlendirilmesi; Gümüşhane İli Örneği. Gümüşhane Üniversitesi Sağlık Bilimleri Dergisi, 7(1), 12-16. 
UNISDR. (2009). $\quad$ Terminology on disaster risk reduction. Erişim adresi https://www.unisdr.org/we/inform/publications/7817 (04.02.2019).

Wachinger, G., Renn, O., Begg, C., \& Kuhlicke, C. (2013). The risk perception paradox -implications for governance and communication of natural hazards. Risk analysis, 33(6), 1049-1065.

Wachinger, G., Renn, O., Bianchizza, C., Coates, T., De Marchi, B., Domènech, L., ... \& Pellizzoni, L. (2010). Risk perception and natural hazards. WP3-Report of the CapHaz-Net Projekt. URL: http://www. caphaz-net. org. Synergien zwischen Naturschutz und KlimaschutzWasser/Gewässer (-Management).

\section{Aim and Scope}

\section{Extended Abstract}

The aim of this study is to determine the risk perception levels of the stakeholders who have roles and responsibilities in disaster management process. The study was carried out in Gümüşhane University in the 2018-2019 Spring Semester. Also, the study is decisive and the results of the study are valid only for the elected heads of departments operating at Gümüşhane University within the scope, and generalization cannot be made. The sections included in the study are Emergency Aid and Disaster Management Department, Occupational Health and Safety Department, Social Service Department, Geophysical Engineering Department, Civil engineering Department, Topographical Engineering Department, Department of Business, Finance Department, Human Resources Management Department, International relations Department, Management Information Systems Department, Sociology department, psychology department, Department of Radio, Television and Cinema, Property Protection and Security Division, First and Emergency Aid Department.

\section{Methods}

Within the scope of the study, interviews were conducted with 16 department heads representing the departments that will be involved in disaster management processes using in-depth interviews, one of the qualitative research methods. The data were obtained through the method of examining the oral interviews, and a "semi-structured interview form" was created to evaluate the risk perceptions of the data sources department heads against emergencies and disasters. Each participant was evaluated by considering this form. Within the scope of the prepared form, categories and sub-criteria were determined to evaluate the risk perceptions of individuals, and the study was carried out based on these criteria.

\section{Findings}

The study has been shaped on 14 different themes. These; themes related to risk perception, themes related to fear, themes related to exposure, themes related to the impact of threats on quality of life, themes related to risk perception, themes related to risk perception, themes related to the state of preparedness, disaster themes related to the plan status, themes related to the plan design status, themes related to the task status of the stakeholders, themes related to the intervention effort status, themes related to the role and task status. Furthermore with this study, when the disaster nature of the region was evaluated, it was determined that the participants perceived the earthquake, which poses a low danger, as the most feared disaster. Most of the participants think; define the ability to cope with disasters as control and they think that the potential to withstand disasters can be created with education, and the training curriculum should focus on factors such as early perception, structural exercises, compliance with regulations, and avoidance. Moreover, the participants think that they will be psychologically, economically, and sociologically affected if they are exposed to any disaster in the region where they live. In addition to, most of the participants think that disasters can recur and consider the possibility of the recurrence of disasters experienced in the past as high.

\section{Conclusion}

In our study, when the risk perceptions of stakeholders who have various expertise and roles in disaster preparedness, mitigation, response, and recovery stages were evaluated, it was concluded that their effectiveness in planning and risk reduction stages was insufficient. The majority of the participants do not intend to be involved in the plan design stages and leave the institutional and 
individual preparation criteria to experts and legislation. Participants avoid taking responsibility, unlike countries in the world where community-based disaster management systems are widespread.

As a result of this study, our recommendations are listed as follows:

- People should be made aware of regional disasters and should be encouraged to take measures against them,

- Intervention and coordination procedures should be carried out by experts and university organizations should also include people who are experts in disasters,

- It is thought that the current preparation can occur with training. For this reason, education curricula should focus on existing dangers, vulnerability, and risks by examining the social, economic, physical, and psychological effects of past disasters,

- Disasters will decrease people's psychological, economic and sociological quality of life. The use of technology should be increased while developing a coping strategy, 